\section{Sob o domínio da urgência: a prática de diretores de hospitais públicos do Rio de Janeiro, Brasil}

\author{
Under the aegis of urgency: management practices \\ by public hospital directors in Rio de Janeiro, \\ Brazil
}

\footnotetext{
1 Escola Nacional de Saúde Pública Sergio Arouca, Fundação Oswaldo Cruz, Rio de Janeiro, Brasil. 2 Instituto de Psicologia. Universidade de São Paulo, São Paulo, Brasil.

3 Programa de Pós-graduação em Psicologia, Universidade Federal Fluminense, Niterói, Brasil.

Correspondência C. S. Azevedo

Departamento de Planejamento e

Administração em Saúde Escola Nacional de Saúde Pública Sergio Arouca Fundação Oswaldo Cruz. Rua Leopoldo Bulhões 1480 , Rio de Janeiro, $R J$ 21041-210, Brasil. creuza@ensp.fiocruz.br
}

\begin{abstract}
This article discusses management practices in public hospitals (general hospitals with emergency services) in the city of Rio de Janeiro, Brazil, based on a psychosociological approach to organizational analysis. Of the 12 existing hospitals, 8 were included in the current study, conducted from July 2003 to April 2004. The research, drawing on hospital directors' narratives, identified three management models. The first focuses on processes of change, highlighting symbolic and imaginative elements for building a vision of the future for the hospitals. The second concentrates on specific projects, which absorbs all the management efforts. A third pattern (predominant in the study) is marked by the struggle to keep the hospital working, with the image of urgency as the driving force. The imposition of continuous action leaves no room for reflection. The crisis in Rio de Janeiro's public hospitals has led to a "wartime" environment and thus the dissemination of the urgencybased model.
\end{abstract}

Hospital Administration; Hospital Chief Executive Officers; Public Hospitals
Creuza da Silva Azevedo 1

Maria Inês Assumpção Fernandes 2

Tereza Cristina Carreteiro ${ }^{3}$

\section{Introdução}

O presente artigo é fruto de uma pesquisa sobre a prática gerencial em hospitais públicos - hospitais gerais com emergência do Município do Rio de Janeiro, Brasil - desenvolvida com perspectiva psicossociológica de análise das organizações, buscando compreender as suas dimensões sociais e intersubjetivas 1 .

A investigação, desenvolvida mediante narrativa dos diretores de hospitais, procurou examinar as visões e os sentidos do exercício da função de direção para os sujeitos e, ao mesmo tempo, compreender o universo da gestão hospitalar pública em hospitais de emergência. O exame das práticas gerenciais norteou-se pela análise das possibilidades e limites de desencadear processos de mudança nesses hospitais.

Os hospitais públicos vêm enfrentando uma crise de governabilidade, de eficiência e qualidade que tem impulsionado inúmeras iniciativas de reformatação dos seus modelos de gestão 2,3,4 .

A temática da gestão foi paulatinamente entrando em cena na área de saúde, tanto como decorrência das tentativas de implementação de um modelo de administração pública gerencial 5 , no contexto de reforma do Estado, como também por seu reconhecimento pelo Movimento Sanitário como fator estratégico na construção do Sistema Único de Saúde (SUS) 4,6,7. Na década de 90, inúmeras experiências de mudanças nos modelos de gestão foram desenvolvidas em 
hospitais públicos e privados brasileiros 2,3,4,5,8, buscando, por um lado, minimizar as dificuldades da burocratização da administração pública e absorver ferramentas gerenciais - ênfase em informações, custos e, por outro, maior democratização dos processos decisórios e dos projetos institucionais.

Embora tenha diagnóstico de longa data 7,9 e venha sendo objeto de inúmeros esforços, a crise dos hospitais públicos prossegue. A complexidade dos processos de mudança nas organizações de saúde tem levado autores do campo da gestão a procurar compreendê-los como processos sociais e organizacionais de difícil controle, para os quais a racionalidade político-estratégica encontra limites, impondo uma atitude de abertura a outras perspectivas que valorizem particularmente os aspectos micro-sociais e o papel dos sujeitos 2,6,10,11,12. Assim, no que se refere mais especificamente a nossa linha de investigação, progressivamente temos procurado novas "lentes" que possam auxiliar na compreensão da dimensão intersubjetiva e inconsciente dos processos organizacionais 10,12 .

Por intermédio da abordagem da psicossociologia francesa, especialmente da leitura de Eugène Enriquez 13,14,15, o fenômeno organizacional passa a ser por nós tratado com base em sua dimensão imaginária, intersubjetiva e grupal. A organização é considerada nesta visão, uma realidade viva, em que os sujeitos vivem seus desejos de afiliação, em que se instaura não somente o jogo do poder, mas também o do desejo, apresentando-se como cenário para paixões presididas pelo amor e também pela violência 13,14. É central nesta perspectiva a teoria psicanalítica de Freud, incorporando também elementos da filosofia e sociologia contemporâneas, com destaque para o pensamento de Cornelius Castoriadis.

A Psicossociologia se interessa pelo indivíduo em situação, recusando separar o indivíduo e o coletivo, procurando em sua análise, articulações entre os condicionantes sociais e psíquicos, compreendendo que os indivíduos se ligam à organização por vínculos afetivos, imaginários e inconscientes 13,14 .

Nesta perspectiva, a organização encontra-se atravessada pelos mesmos problemas que caracterizam o vínculo social: ambivalência, ilusões e ainda pela violência, ataque aos vínculos, restringindo então as possibilidades de regulação e de governabilidade 13,14,15.

Em analogia à leitura de Merhy 16 sobre a natureza do trabalho em saúde proponho tratar a gestão e o trabalho gerencial como "trabalho vivo em ato”, que se realiza entre sujeitos, emergindo, portanto, no contexto intersubjetivo. Por essa compreensão, os processos de mudança apóiam-se no favorecimento da maior circulação da palavra e autonomia dos sujeitos, na busca de novos sentidos para o trabalho, implicando processos identificatórios e imaginários que possibilitem abrir brechas no imaginário organizacional dominante.

Os dirigentes ocupam potencialmente uma função estruturante, de intermediação, também de apoio e sustentação nas organizações. $\mathrm{Na}$ função de liderança, eles seriam capazes de articular o laço psíquico e social entre os membros do grupo 17. Interrogamos, no entanto, sobre a possibilidade de exercício desta função no contexto em que vivem as organizações públicas de saúde.

As modalidades de prática gerencial, objeto central na discussão deste artigo, resultam de uma tentativa de construir modelos de análise do trabalho gerencial. Em uma primeira modalidade se vislumbra o desenvolvimento de processos de mudança, ganhando destaque os elementos simbólicos e imaginários que contribuem para a construção de uma visão de futuro dos hospitais. Uma segunda modalidade de prática pauta-se por projetos específicos que se tornam objeto de investimento da gestão. Um terceiro modelo, central na investigação realizada, estaria marcado pela luta para fazer funcionar, tendo como motor o imaginário da urgência. Na urgência não há estratégia, só ato. A ação contínua se impõe, não havendo brechas para a reflexão. A crise dos hospitais públicos no Rio de Janeiro foi ganhando vulto sem precedentes, levando a um contexto de "guerra" e de generalização do modelo da urgência.

\section{Metodologia}

Este trabalho analisa a gestão dos hospitais públicos mediante depoimentos de seus diretores. Do ponto de vista metodológico, a abordagem qualificada como Narrativas de Vida 18,19 orientou a investigação da prática gerencial, pautando-se tanto pela perspectiva da Etnossociologia de Bertaux 20, buscando compreender a gestão hospitalar pública no Rio de Janeiro como um mundo social e as narrativas como práticas em situação, como também, pela abordagem psicossociológica 21, e assim, procurando considerar os processos imaginários que atravessam o relato dos entrevistados, tratando-o então não apenas como um discurso singular, mas também como expressão da cena organizacional e institucional.

Compreendemos os entrevistados como sujeitos-porta-vozes 17 que expressam as possibilidades institucionais de exercício da gestão. 
$\mathrm{Na}$ análise da experiência gerencial procuramos mostrar como se movem os diretores, a abrangência e os focos das ações gerenciais, tanto no âmbito interno do hospital como externo, os projetos em andamento, o sistema de direção que se estrutura. Tal análise encontra-se atravessada por elementos da abordagem psicossociológica, encontrando-se então preocupações quanto à circulação da palavra, a repartição de lugares, as possibilidades da coesão e especialmente a dimensão imaginária emergente.

$\mathrm{O}$ universo da investigação foi delimitado a diretores de hospitais gerais com emergência vinculados à rede pública de assistência nas diferentes esferas de governo: federal, estadual e municipal.

A seleção dos entrevistados considerou também a experiência gerencial anterior do diretor. Foram selecionados prioritariamente diretores com ao menos uma experiência anterior como diretor de hospital público. Em um universo de 12 hospitais, 8 foram incluídos neste estudo:

- Secretaria Municipal de Saúde do Rio de Janeiro (SMS-RJ): dois hospitais originalmente de sua rede de hospitais gerais de emergência e dois hospitais municipalizados - historicamente vinculados ao Instituto Nacional de Assistência Médica da Previdência Social (INAMPS) e posteriormente ao Ministério da Saúde e no momento da pesquisa ligados à SMS-RJ;

- Secretaria Estadual de Saúde do Rio de Janeiro (SES-RJ): três hospitais de emergência originalmente da rede da SES-RJ;

- Ministério da Saúde: a única unidade hospitalar com emergência do Rio de Janeiro.

As entrevistas foram realizadas ao longo de um período de dez meses - entre julho de 2003 e abril de 2004. Os nomes dos diretores são fictícios e os hospitais foram identificados por letras.

É importante ainda esclarecer que foram seguidos os princípios éticos contidos na Declaração de Helsinki (1989), que fundamenta a resolução do Conselho Nacional de Saúde (1996) quanto às diretrizes de pesquisa envolvendo seres humanos.

\section{As modalidades de prática gerencial}

Considerando as experiências anteriores dos entrevistados na função de direção de hospital, apresentam-se, por um lado, vivências de realização, capacidade de desenvolvimento de projetos, estando presente um imaginário de potência e de possibilidades de um melhor funcionamento dos hospitais; por outro lado, os relatos tratam de situações de crise, enfrentamentos e, por vezes, exonerações traumáticas. Os obstá- culos são muitos e ganham destaque tanto nas experiências anteriores quanto nas atuais: há um conjunto de determinações de origem externa - pressões políticas, escassez de recursos, condições de abastecimento e funcionamento deficientes, precariedade na política de recursos humanos. Os diretores se deparam com as pressões de fornecedores, com a "privatização" dos hospitais pelos interesses políticos e corporativos de toda ordem. Do ponto de vista interno, manifestam-se as coalizões de poder, emergindo oposições e adesões. São freqüentes situações de grande agressividade e maus-tratos à população. Enfim, trata-se de um contexto de baixa governabilidade, expressão de forças instituídas, contra as quais, a nosso ver, os diretores entrevistados procuram lutar. A superlotação e a pressão por atendimento, as restrições quanto às condições materiais para o atendimento, constituem um quadro de precariedade que se torna importante fonte de sofrimento.

Com base neste quadro, a investigação aprofundou a análise das práticas gerenciais dos diretores, desenvolvendo três modelos/modalidades de prática. A este respeito, algumas considerações gerais tornam-se importantes, particularmente sobre o significado e as implicações de cada uma delas.

Primeiramente, evidencia-se o condicionamento das práticas gerenciais nos hospitais pelas políticas governamentais expressas no âmbito das Secretarias de Saúde e do Ministério da Saúde, em particular aquelas relativas à área orçamentário-financeira e de abastecimento. Os modelos gerenciais adotados pelos órgãos de governo e as restrições de financiamento têm repercussão direta, limitando as possibilidades de desenvolvimento de experiências criativas por parte da direção dos hospitais.

Na conjuntura estudada, o contexto mais crítico é o dos hospitais vinculados à SMS-RJ que vivem uma situação de intensa crise, tendo levado à perda da gestão plena do sistema de saúde municipal.

Enfocando agora as três modalidades de prática gerencial consideradas na análise das experiências, estas, na verdade, mostram-se como pólos extremos de uma realidade mais matizada. Expressam, talvez, tipos ideais, enquanto a realidade mostra-se mais heterogênea.

No primeiro modelo, no qual se inserem duas das experiências analisadas, a de Márcio (hospital L/SMS-RJ) e Fernando (hospital C/Ministério da Saúde), a gestão representaria uma força no sentido da mudança, e sua perspectiva de trabalho se desenvolve em torno de uma representação acerca do que deve ser o hospital. Essa representação fundaria uma proposta ou projeto para 
o hospital favorecendo processos de ligação que procuram ser trabalhados no nível coletivo.

Porém, participar de um projeto, como afirma Carreteiro 22, implica sonhá-lo, imaginá-lo, elaborá-lo ou até mesmo abandoná-lo. Como processo coletivo, apóia-se em um imaginário social comum, envolvendo processos identificatórios e mesmo algum nível de idealização 14 .

O contexto contemporâneo, no entanto, impõe importantes restrições à construção de ideais coletivos. A sociedade ocidental contemporânea é marcada por um déficit de ideais e referências 23 , pelo abandono do discurso de emancipação, pela desregulamentação 24 , pelo recrudescimento do domínio privado em detrimento do público 25 , pelo enfraquecimento do laço social 26 , entre outras características, conformando um contexto, a princípio, desfavorável à maior responsabilidade social, à cooperação, enfim, aos processos identificatórios necessários às construções coletivas.

Somam-se ainda as dificuldades advindas do contexto específico das organizações públicas de saúde no Brasil. Supomos que hoje seja dominante nos serviços públicos de saúde um imaginário da impotência, do descrédito, do conformismo, alimentados por uma situação de não reconhecimento, falta de perspectiva e temor quanto ao futuro - tanto dos funcionários quanto dos hospitais, submetidos à grande precariedade. Neste cenário emergem os interesses corporativos e os "esquemas de trabalho". Perante tudo isso a construção da mudança nos hospitais públicos é um árduo caminho buscando abrir fendas no instituído, sendo objeto de grande oposição.

O segundo modelo, ao qual correspondem três experiências (Oswaldo, hospital K/SES-RJ; Renato, hospital I/SES-RJ; a primeira fase de Vicente, hospital N/SMS-RJ), representaria a tentativa de estabelecimento de certos objetivos e consequëntemente de projetos, porém específi$\cos$ - por exemplo, a reorganização da porta de entrada, o sistema de dose unitária de medicamentos, a informatização etc. -, não constituindo um processo mais amplo de mudança, pois não impactam a visão e a perspectiva que se tem do hospital, suas significações imaginárias, seu projeto institucional. Talvez possa significar a possibilidade de mover positivamente o hospital, apontando, em um nível micro, possibilidades de influenciar seu futuro.

O terceiro modelo - dominante no estudo realizado, representado pelas experiências de Antônia (hospital D/SES-RJ), Estela (hospital Q/SMS-RJ); Cláudia (hospital E/SMS-RJ) e pela segunda fase de Vicente (hospital N/SMS-RJ) estaria pautado pelo imaginário da urgência, pela busca da operacionalidade, pelo esforço para fa- zer funcionar. A luta pela sobrevivência, neste caso, ocuparia de forma absoluta a atenção da direção, especialmente manifesta na luta para dispor de insumos, de equipamentos, de uma estrutura física adequada, enfim, de condições de funcionamento que possibilitem o hospital continuar atendendo à sua demanda. Esse modelo seria fruto do contexto institucional, sobretudo das Secretarias de Saúde, considerando a baixa capacidade de suprir as necessidades dos serviços de saúde, o baixo nível de investimento que vem sendo feito e a falta de autonomia dos hospitais. Em um outro plano de análise, tal modalidade de prática evidenciaria o imaginário dominante na sociedade contemporânea relativo ao tempo, com seus efeitos na maneira de viver e trabalhar pautados pelo imediatismo, pelo curto prazo. Assim, a compressão do tempo, sua aceleração, afeta os indivíduos que passam a focar somente o presente, incapazes de viver algo além do presente imediato. Por outro lado, esse homem, mergulhado na instantaneidade, vive como se a velocidade de solução dos problemas pudesse gerar sentido à sua ação 27 . Assim parece acontecer, como será visto posteriormente, com alguns dos diretores entrevistados: a urgência produz um sentido à sua prática.

As experiências destes diretores indicam o quanto essas modalidades de prática gerencial encontram-se na encruzilhada entre vários planos de determinação. Por um lado, elas são expressões da capacidade dos diretores, associamse às suas trajetórias profissionais, mas ao mesmo tempo expressam processos intersubjetivos que se constroem na organização compreendida como instância grupal e, num outro nível de análise, tais modalidades têm origem em processos institucionais e macro-sociais.

\section{Construindo a mudança}

A mudança a que nos referimos tem por base certa compreensão que vem atravessando o Movimento Sanitário ${ }^{4,28}$. Trata-se da construção de processos que fortaleçam a dimensão pública e social das organizações públicas, voltadas para a defesa da vida e a democratização da gestão do sistema de saúde. Tais mudanças devem levar a nova forma de organização dos serviços e de sua gestão, propiciando maior responsabilidade institucional para com os resultados do trabalho e também uma perspectiva mais técnica e profissional da gestão.

As experiências relatadas por dois diretores - Márcio (SMS/RJ) e Fernando (Ministério da Saúde) -, não apenas as atuais mas também as anteriores são ricas como possibilidades de 
construção de uma prática na gestão pública pautada por um olhar mais técnico - pela identificação de potencialidades, de melhoria da infraestrutura e dos sistemas de monitoramento e, do ponto de vista político, pela construção uma base participativa, colegiada de direção. Destacam-se no trabalho de gestão tanto de Márcio quanto de Fernando uma sistemática de trabalho de direção ampliada e, assim, tentativas de um modo mais coletivo de processamento de problemas. Apesar do domínio de forças instituídas que fortalecem a impotência e a inércia nos serviços públicos, essas experiências apostam na mudança pela construção de um plano de trabalho, de um projeto gerencial e assistencial, representando simbolicamente que é possível mudar para melhor, que existem condições para construção de um projeto para o desenvolvimento dessas unidades hospitalares.

Os processos relatados traduzem, decerto, o imaginário desses diretores sobre a mudança a ser construída, estando atravessados pela idealização e pela crença desses sujeitos. Contudo, a ilusão é necessária - é o que fecunda o real 14 - e é também produtora de efeitos nos hospitais. Assim, nessas experiências os diretores procuram canalizar o investimento dos profissionais, buscando favorecer uma outra construção imaginária.

As características dessas experiências de gestão que procuram construir condições para processos de mudança expressam-se nas estratégias de trabalho e no sistema de direção que esses diretores procuram desenvolver. No trabalho gerencial, ganha ênfase o papel de articulação externa, com instituições de saúde - buscando levar as propostas do hospital para o âmbito do SUS - com outras instituições públicas, mas também com o setor privado, buscando apoio para o funcionamento do hospital. Como foco do trabalho também é realçada a dimensão interativa e viva de interface com os profissionais, seja para construção de acordos, seja para o enfrentamento de conflitos e construção de relações de confiança. A montagem de dispositivos no sentido de construção de pactos quanto aos rumos do hospital e quanto ao seu modo de funcionamento interno também é central, ganhando importância a constituição de uma estrutura orgânica de gestão.

A experiência de direção atual de Márcio (hospital L/SMS-RJ), iniciada em janeiro de 2003, desenvolve-se com base num projeto, acordado com o Secretário de Saúde, de acabar com o sistema de cooperativa no hospital, que desde sua inauguração vem funcionando com profissionais terceirizados. À perspectiva de alteração para melhora da relação trabalhista com seus funcionários, associam-se outros eixos de trabalho, não só os gerenciais mencionados antes, mas particularmente a melhoria de condições de recepção ao paciente e uma nova organização do trabalho assistencial.

Márcio ressalta o reconhecimento de melhorias na capacidade de funcionamento e qualidade implicando uma imagem de maior potência do hospital: "hoje ninguém tem dúvidas que o hospital L está em pé de igualdade com os maiores hospitais públicos de emergência do Rio de Janeiro".

Apesar do contexto de centralização administrativa da SMS-RJ, a experiência no hospital L, como as anteriores conduzidas por Márcio, mostra-se como projeto especial para a SMS-RJ, propiciando maior investimento e autonomia do diretor em sua condução.

A experiência de Fernando, no hospital C (Ministério da Saúde), há quatro anos no exercício da direção por ocasião das entrevistas, expressa também a possibilidade de construção de processos de mudança nos hospitais.

Do ponto de vista interno, o entrevistado identifica alguns elementos que fariam parte do que percebe como seu próprio "padrão gerencial”, certo modo de fazer gestão hospitalar: (1) a conformação de uma equipe de gestão mais profissional, que permita uma boa infra-estrutura, (2) um trabalho profissional da comunicação social e (3) o desenvolvimento de um processo de Planejamento Estratégico, como estratégia de pactuação de um projeto institucional. Tal processo se inicia no hospital C após os seis primeiros meses de trabalho e apesar da direção estar "debaixo de pancadaria com o Sindicato (...) debaixo de uma agenda, do ponto de vista operacional, pesadíssima" expressando, na visão de Fernando, que a direção "de uma forma ou de outra, já tinha conquistado uma certa credibilidade que pôde trazer as pessoas...".

Considerando que o imaginário instituído nas organizações públicas é de descrédito e impotência, poder pensar sobre o futuro é poder abrir brechas para uma outra construção. Tal processo parece propiciar um reconhecimento mais positivo do papel do hospital e dos funcionários em oposição ao lugar da negatividade - desqualificação das organizações públicas e seus funcionários - que é dominante e que fundamenta certa invalidação simbólica dessas organizações.

A idéia de aumento da auto-estima dos funcionários, presente no depoimento dos dois entrevistados - Fernando e Márcio -, associada ao reconhecimento de um melhor funcionamento dos hospitais, seria uma expressão do tipo de investimento psíquico que, na visão dos entrevistados, estaria presente nos processos de gestão nas duas experiências. 
Esses processos sugerem a constituição de um caminho favorável à ligação, ao vínculo - e assim à expressão da pulsão de vida -, um caminho "propositivo" em oposição e em luta contra o "denuncismo" - fruto da ação de forças de desligamento, manifestação da pulsão de morte questões intersubjetivas tratadas por Enriquez 14 , que se fazem presentes nos processos organizacionais e, particularmente, nos processos relatados.

É importante frisar que os diretores encontravam-se entusiasmados, um deles se dizendo “apaixonado" pela experiência. Ainda que eles tenham descrito processos de oposição e boicote à direção, talvez tenham subestimado as forças de oposição às propostas.

Embora com cautela para não assumirmos o entusiasmo do narrador, compreendemos que, no contexto atual, marcado pela desagregação e falta de idealização, conduzir um processo que leve a se interrogar o papel do hospital no SUS, procurando identificar suas capacidades e debilidades, além instigar o debate sobre seu modo de funcionamento e seu futuro, podem favorecer uma construção grupal ancorada em significações imaginárias. É um contexto supostamente propício ao que Castoriadis 29 denominou "imaginário social instituinte" e ao exercício do que que Kaës 17 definiu como função intermediária pelo líder e pelo grupo.

De todo modo é preciso considerar que tais experiências, como todas as práticas organizacionais, estão sob o fio da navalha, no sentido de poderem engendrar submissão e/ou criação e autonomia. É preciso reconhecer o embate entre as forças dominantes da heteronomia 29 enquanto expressão do conformismo e da repetição, forças disjuntivas 13,14, e aquelas que procuram favorecer o vínculo, o reconhecimento e a construção coletiva.

A saída de Fernando do hospital C, ocorrida por exoneração em dezembro de 2004, evidenciou o mal-estar por que passava o hospital e a potência das forças instituídas. Do ponto de vista político é fruto da condução do Ministério da Saúde, mas também do contexto conflitivo do hospital. As denúncias que desencadearam a crise na gestão hospital C e a instauração de um processo administrativo contra o diretor se originaram, no hospital, em um grupo ligado ao Sindicato dos Médicos. Por outro lado, merece ser destacada a capacidade de mobilização de parte dos funcionários e profissionais, denunciando a impropriedade das acusações, procurando defender o diretor e o projeto de trabalho em curso. Durante o processo, houve um movimento de convocação em prol da defesa do hospital e de sua gestão. Apesar de ter-se consumado a exone- ração do diretor e dos processos violentos que a envolveram, especialmente para o diretor, é fundamental por em destaque a capacidade de mobilização dos profissionais com outros fins que não o "denuncismo", buscando dar visibilidade aos avanços e melhorias do hospital e a defesa da equipe de direção, apontando, dessa forma, para a construção de outros significados sobre o trabalho e a vida no hospital C. Há uma dinâmica entre as forças da heteronomia, do conformismo e aquelas que buscam mudanças e, portanto, a constituição de um imaginário motor na acepção trabalhada por Enriquez 14. De todo modo, a exoneração não deve ser minimizada, pois representa uma situação de ruptura do projeto em andamento.

Finalizando a discussão das experiências tidas como capazes de desencadear processos de mudança nos hospitais, apenas duas das oito estudadas, é importante assinalar que apesar do contexto de restrições à construção de ideais, os processos tratados pelos entrevistados podem representar um movimento de construção de um novo imaginário. Imaginário dos diretores, correspondendo às suas próprias ilusões e idealizações, mas também partilhado, não de maneira unificante, pela organização, e sim por alguns grupos no hospital. Imaginário motor que abre para outras possibilidades, mas que permanece em conflito com o imaginário enganoso, dominante, marcado pela impotência, desilusão e pelo corporativismo.

\section{Desenvolvendo projetos específicos}

Serão consideradas a seguir, aquelas experiências em que, além da gestão dos problemas cotidianos, alguns projetos, embora recortados e específicos, tornam-se norteadores da ação gerencial. Não constituem um processo amplo de mudança, pois não produzem efeitos sobre a visão que se tem do hospital - seu projeto assistencial ou gerencial. Três experiências encontram-se neste grupo: duas em hospitais da SES-RJ e outra em um hospital da SMS-RJ.

Embora na condução do hospital I/SES-RJ, Renato não tenha desenvolvido de forma articulada, um projeto para o hospital, voltou-se para o fortalecimento de um sistema participativo de gestão, discutindo resultados, problemas e o andamento dos projetos. Foram destacados o de informatização do hospital, o de Saúde do Trabalhador, o de reorganização da Porta de Entrada e de Acreditação Hospitalar.

Ainda que Renato procurasse solucionar os problemas que se apresentavam, ele não se mostrou absorvido pela lógica da urgência, pelo es- 
forço absoluto para fazer funcionar o hospital. Há, por conseguinte, algum afastamento da operação, possibilitando a constituição de grupos de trabalho voltados para determinada tarefa.

Vicente, outro entrevistado que faz parte deste grupo, diretor do hospital N/SMS-RJ, apresentou uma situação diferenciada. Exercendo a direção do hospital há oito anos, identifica ao longo do período, duas fases diferentes de trabalho. A primeira, chamada "anos dourados", se caracteriza por melhores condições materiais, por um foco na organização interna do hospital, pela tentativa de debater novos valores para a assistência. Uma segunda fase seria a dos "anos da crise", pautada pelo apagar incêndio, por dificuldades quanto às condições de trabalho, que se agravaram mais recentemente, com a crise da SMS-RJ que, na visão do entrevistado, transformou os dirigentes em "síndicos", lutando exclusivamente pela sobrevivência. Logo, essa experiência pode, em seu primeiro momento, ser incluída na modalidade dois de prática gerencial, constituindo-se alguns projetos, enquanto a segunda fase se insere claramente no modelo da urgência.

Encontram-se nesta experiência, práticas distintas vividas pelo mesmo gestor, no mesmo hospital. Nos "anos dourados" existiam "planos de trabalho" refletindo uma prática pró-ativa e que procurou envolver uma idéia de planejamento. Os bons resultados do hospital se refletiram, na visão do diretor, na conquista do prêmio estadual de qualidade. Mesmo que não tenha se conformado um projeto de gestão, com uma estrutura coletiva de direção, nem um delineamento claro quanto ao projeto assistencial, há um esforço para o desenvolvimento do hospital e definição de objetivos. Do mesmo modo, ganhou importância o trabalho com indicadores, e assim o acompanhamento do desempenho do hospital. O contexto da gestão era favorável: estavam se renovando seus equipamentos e a infraestrutura estava funcionando melhor. De 2001 em diante, a crise política e também gerencial da SMS-RJ vem tendo conseqüências importantes nas condições de funcionamento do hospital. Vicente se diz, então, "refém da crise". No próximo item será analisada, no contexto da crise da SMS-RJ, sua experiência de luta para garantir o funcionamento do hospital.

Finalizando a análise da modalidade dois de gestão, os projetos específicos podem ser tidos como estratégias de trabalho dos diretores na busca de uma ação mais sistêmica sobre a organização e seus problemas, permitindo, ao mesmo tempo, dar visibilidade às "realizações da gestão”. Em outro plano de análise, tais projetos apóiam os diretores na elaboração do seu papel no hospital e cumprem uma função tranqüiliza- dora e organizadora perante as pressões de toda ordem que chegam à direção e que expressam o desgoverno e o descontrole que atravessam esses hospitais. Por fim, compreendemos, considerando o contexto atual dos serviços públicos de saúde - o clima de descrédito, as dificuldades de cooperação e o imaginário da impotência - que o investimento em "projetos específicos" pode estar refletindo "o possível" - um pequeno ideal, passível de investimento pelos indivíduos.

\section{Sob o domínio da urgência}

A luta para fazer funcionar o hospital e dispor dos insumos necessários para realização das atividades assistenciais como um foco absoluto, absorvendo integralmente a atenção do diretor é compreendida como um sintoma de um funcionamento pautado pela urgência, devendo ser reconhecida não apenas como uma construção individual, mas como um analisador do que se passa nas organizações e respectivas instituições 27 .

Quatro experiências encontram-se neste grupo. Inicialmente será considerado o contexto da SES-RJ, menos crítico que as circunstâncias atuais que envolvem a gestão na SMS-RJ.

Na experiência desenvolvida no hospital D, Antônia mostra-se muito próxima à ação, voltada basicamente para solução dos problemas diários, embora reconheça, por um lado, a necessidade de um plano de longo prazo e mencione, por outro, projetos que foram desenvolvidos no hospital.

"No meu trabalho do dia a dia, eu pouco planejo, eu mais apago incêndio. Isso está errado, a gente até sabe que não é por aí (...) E o hospital D me ensinou muito isso também (...) 'Qual é o filé do dia?' Separar o osso do filé, priorizar e rapidamente resolver. Sempre tem situações de emergência para resolver" (Antônia).

Em seu depoimento, Antônia destacou os esforços para garantir o funcionamento do hospital, associados por um lado, à escassez de recursos, falta de investimento, centralização, e, por outro, ao excesso de demanda fruto da desorganização da rede de serviços. A ausência de uma rede de serviços vem determinando uma sobrecarga aos hospitais de emergência, gerando vivências de descontrole e angústias associadas a um trabalho excessivo, porém ao mesmo tempo insuficiente. A referida entrevistada, em seu relato, mostra-se claramente porta-voz de uma circunstância extremamente difícil e que vem afetando todos os hospitais de emergência.

Apesar da angústia decorrente da improvisação e de uma prática orientada pelo "problema do 
dia" surge certa adaptação a esse contexto de urgência e até mesmo prazer com relação ao papel de "operacionalizador do sistema". A prontidão permanente, a ação contínua parece funcionar como um antídoto contra a incerteza, evitando contato com os conflitos. Assim, o imediatismo e o curto prazo são produtores de sentido e cumprem um papel defensivo.

Nas narrativas de Antônia (SES-RJ) e também de Estela (SMS-RJ), por mais que se percebam críticas e também angústias pela situação de precariedade, parece coexistir certa vaidade por serem capazes de sobreviver em contexto adverso e, até mesmo, certo prazer de identificar e enfrentar o "filé do dia". Nestes casos, haveria uma ressonância entre a urgência exterior e a urgência interior: “trabalhar na urgência, 'tomar' as urgências pode se constituir um meio de afirmação pessoal, uma forma de assegurar seu poder, ou ainda uma maneira de resposta à ansiedade" 27 (p.103).

Para Antônia e Estela, lutar diariamente para dar conta dos inúmeros problemas do hospital, agindo rapidamente sob tensão, acrescenta intensidade à vida, funcionando imaginariamente, como domínio do tempo: “...eu digo assim: 'ser diretora é muito emocionante. Não dá tempo de ter depressão (...)' É uma terapia fantástica para os deprimidos: ou você morre, ou você fica para cima" (Estela).

O funcionamento psíquico baseado no modelo da urgência leva à compressão do tempo. Logo, as situações de urgência configuram possibilidades para comportamentos compulsivos correspondendo à passagem ao ato. Mostra-se, assim, uma tirania da urgência. “...O tempo de reflexão é inexistente, agir é uma necessidade imperativa para atender a violência da angústia sentida pelo sujeito" 27 (p. 264).

Passamos agora à análise das experiências de Vicente e Cláudia, emblemáticas na capacidade de expressão da crise gerencial e assistencial vivida pela SMS-RJ. A crise levou-os a viver sob absoluto domínio da urgência, exclusivamente no "apagar incêndio", manifestando-se como "total incapacidade de desempenhar o papel de gestão". A crise da SMS-RJ, bem mais aguda que a SES-RJ, pode ser compreendida pela perspectiva de Kaës 17,30,31 como produtora de falhas nas formações intermediárias. Assim, as funções de suporte, apoio, sustentação potencialmente exercidas pela direção enquanto liderança mostram-se fragilizadas, conformando então um contexto favorável a vivências de desamparo.

A SMS-RJ vem desde 2004 vivendo uma crise administrativa que se expressa como crise assistencial nos hospitais, sendo fonte de problemas críticos enfrentados diariamente pelos diretores. Foram relatados graves problemas de manuten- ção de equipamentos médico-cirúrgicos, falta de insumos, especialmente medicamentos. Os contratos de manutenção não foram renovados, a prefeitura encontrava-se com dívidas junto a inúmeras empresas, que estavam na iminência de suspensão de serviços, ou de alimentação ou de lavagem de roupa, por exemplo. Faltavam insumos em geral, havia escassez de medicamentos básicos. Os equipamentos não estavam sendo consertados nem repostos. Vicente é enfático quanto à extensão da crise. Em toda sua vida no serviço público nunca viveu nada dessa ordem.

Esse contexto de total precariedade impede que os profissionais e também os diretores experimentem o trabalho como realização de si e construção de identidade, como apontado por Dejours ${ }^{32}$. Tal situação funciona como obstáculo ao reconhecimento das contribuições dos trabalhadores à organização do trabalho.

A seguir, será tratada, neste contexto de crise da SMS-RJ, a experiência de Cláudia (SMS-RJ), que evidencia a situação dramática vivida nos hospitais da prefeitura.

Cláudia, diretora do hospital E, vinculado anteriormente ao Ministério da Saúde e municipalizado em 1999, traz em seu depoimento imagens contundentes sobre a situação de caos vivida no hospital e a luta para mantê-lo em funcionamento. Descreve, além dos problemas operacionais atuais, situações estruturais de intensa precariedade colocando em xeque a cada momento o funcionamento do hospital, exigindo um esforço intenso para realização das atividades. A improvisação dá o tom à organização do espaço hospitalar, sendo destacada a disposição caótica dos serviços na planta, gerando inúmeros problemas. A situação física do hospital, tão enfatizada pela entrevistada, surge como expressão simbólica do lugar social negativo ocupado pelo hospital público brasileiro.

A luta constante pela sobrevivência tem como referência as condições materiais, sejam aquelas relativas ao espaço - estrutura física, sua deterioração, desorganização -, sejam também aquelas referentes às condições de suprimento $\mathrm{e}$ infra-estrutura.

Sobre a crise atual, alguns fragmentos são contundentes:

"Eu pensava que o fundo do poço existia. Ele é virtual. Eu nunca imaginei que a gente chegasse à situação que estava no ano passado, esse ano consegue estar pior. Eu estou sem contrato de manutenção predial, eu fiquei sem contrato da parte de refrigeração e câmara mortuária", "E o dinheiro não dá, porque eu também não tenho remédio nenhum" e "Não tem morfina. Eu sou pólo de oncologia. Só existem três pólos: eu não tenho um quimioterápico. Os pacientes choram, 
todo dia, na minha porta. Estão interrompendo tratamento!".

A metáfora do "fundo do poço virtual" revela o sentido da mudança que vem ocorrendo nos hospitais da SMS-RJ: as condições de trabalho - físicas, estruturais, dos recursos disponíveis, de coordenação, da comunicação - pioram drasticamente. Embora exista um fundo rotativo, que é um sistema de pronto pagamento gerenciado pela direção da unidade hospitalar, ele é considerado pelos diretores como muito limitado para fazer frente a todo o custeio do hospital.

A situação de intensa precariedade e a gestão voltada exclusivamente para a urgência tornase a base para o imaginário de "guerra" que se estabelece.

Enquanto a morte em um hospital que dispõe de recursos adequados para a assistência surge como o imponderável, no contexto de absoluta escassez e descontrole a luta contra a morte toma contornos de uma luta contra a precariedade, em seu limite. Um hospital onde faltam medicamentos básicos, onde existem problemas de esterilização, onde os pacientes são colocados até mesmo em cadeiras, torna-se um espaço de violência, de impotência, de imenso desamparo.

A urgência tratada particularmente porVicente e Cláudia não significa exclusivamente adotar como foco a operacionalidade, "botar para funcionar". Envolve a luta contra a morte em suas várias dimensões: morte do hospital, morte da população, morte dos funcionários, implicando um contato com sua própria morte e a do outro.

A solidão hierárquica e o nível de responsabilidade oriunda do cargo de direção somam-se a outros fatores a desencadear sofrimento. Em um contexto de estresse profissional "o sujeito funciona, então, como uma caixa de ressonância dos múltiplos problemas ou múltiplos conflitos da organização...” 33 (p. 178). O sofrimento “inibe as capacidades e destitui a linguagem (...) o sujeito está isolado, exilado no tempo e no espaço, 'pregado', destinado a um aqui impossivel de ser transposto, preso no presente indefinido do sofrimento" 34 (p. 19).

A aguda crise da assistência hospitalar vivida no âmbito da SMS-RJ, expressa nos depoimentos dos diretores entrevistados, ganhando contornos particularmente dramáticos em dois casos, foi se expandindo, abrangendo toda a rede de hospitais da prefeitura, representando uma situação de crise na saúde nunca antes vivida. Apoiando-nos em Giust-Desprairies 35, nós a consideramos como uma situação brutal que se traduz por uma desregulação total, expressando-se na experiência subjetiva, organizacional e social como desconstrução. A violência e um imaginário mortífero ganharam espaço. A crise se inscreve no imediato, não sendo possível representar o futuro. Há um aprisionamento no tempo presente, no imediato, na urgência.

\section{Considerações finais}

Ao fazer um balanço final, é preciso realçar que em apenas duas das oito experiências foi possível identificar processos de mudança. Uma dessas experiências, no entanto, foi interrompida - a de Fernando no hospital C - atropelada pela exoneração do diretor e a saída de toda a equipe de direção. Com relação a outra experiência, a de Márcio no hospital L, a situação de crise da SMSRJ também atingiu este hospital. Pela imprensa (O Globo 2005; 7 jun., p. 18), tivemos acesso a notícias de greve dos médicos vinculados à cooperativa médica que presta serviços ao hospital, por falta de pagamento. Por conseguinte, a expectativa de um novo modo de funcionamento com os médicos concursados vem encontrando dificuldades para se concretizar.

Considerando a força da urgência e, sobretudo, o contexto de hiper-urgência e colapso que caracterizou a crise da assistência hospitalar no Rio de Janeiro, de 2004 estendendo-se até 2005, como também as dificuldades para construir o "dia seguinte" da crise, chegamos a um balanço nada animador.

Sob o domínio absoluto da urgência, os hospitais foram se tornando espaços para manifestação de diversas formas de violência, de degradação, de desvalorização da vida, configurando então um quadro de mudanças para pior: os hospitais públicos tornaram-se palco de cenas dramáticas, expressando a dificuldade de atender e ser atendido. Essas condições, mais que nunca, vêm levando esses hospitais a ocuparem um pólo contra-identificatório, minimizando, então, as possibilidades de afiliação e os vínculos de pertencimento por parte de seus profissionais.

Podemos supor que essa experiência de crise produza efeitos sobre as capacidades futuras de ilusão, idealização e crença dos sujeitos - gestores, profissionais de saúde, fortalecendo a apatia, o conformismo, portanto as forças da heteronomia 29 , contribuindo ainda para a manutenção de um modelo de ação contínua, pautado pelo imediatismo.

Lamentavelmente, é necessário reconhecer a fragilidade dos movimentos de mudança, no sentido compreendido pelo Movimento Sanitário, frente aos processos mortíferos dominantes na sociedade e que têm emergido de forma tão brutal no âmbito dos serviços públicos de saúde, particularmente no Rio de Janeiro. 


\section{Resumo}

Este artigo apresenta o resultado de uma pesquisa sobre a prática gerencial em hospitais públicos - hospitais gerais com emergência do Município do Rio de Janeiro, Brasil-, desenvolvida mediante a perspectiva psicossociológica de análise das organizações. Em um universo de 12 hospitais, 8 foram incluídos no estudo, realizado entre julho de 2003 e abril de 2004. A investigação, desenvolvida pela narrativa dos diretores de hospitais, identificou três modalidades de prática gerencial. Em uma primeira, vislumbram-se processos de mudança, ganhando destaque elementos simbólicos e imaginários envolvidos na construção de uma visão de futuro dos hospitais. Uma segunda modalidade de prática pauta-se por projetos específicos que se tornam objeto de investimento da gestão. Um terceiro modelo, dominante na investigação, estaria marcado pela luta para fazer funcionar o hospital, tendo como motor o imaginário da urgência. A ação contínua se impõe, não havendo brechas para a reflexão. A crise dos hospitais públicos no Rio de Janeiro foi levando a um contexto de "guerra" e de generalização do modelo da urgência.

Administração Hospitalar; Diretores de Hospitais; Hospitais Públicos

\section{Colaboradores}

C. S. Azevedo realizou a pesquisa, a análise dos resultados e a redação do artigo. M. I. A. Fernandes e T. C. Carreteiro contribuíram no desenvolvimento teóricometodológico da pesquisa, na concepção do artigo e na discussão de seus resultados.

\section{Referências}

1. Azevedo CS. Sob o domínio da urgência: o trabalho de diretores de hospitais públicos do Rio de Janeiro [Tese de Doutorado]. São Paulo: Universidade de São Paulo; 2005.

2. Cecílio LCO, Mendes TC. Propostas alternativas de gestão hospitalar e o protagonismo dos trabalhadores: por que as coisas nem sempre acontecem como os dirigentes desejam? Saúde Soc 2004; 13:39-55.

3. Cecílio LCO. A modernização gerencial dos hospitais públicos: o difícil exercício da mudança. Rev Adm Pública 1997; 31:36-47.

4. Cecílio LCO, organizador. Inventando a mudança na saúde. São Paulo: Editora Hucitec; 1994.

5. Machado CV. Novos modelos de gerência nos hospitais públicos: as experiências recentes. Physis 2001; 11:105-98.

6. Campos GWS. Um método para análise e co-gestão de coletivos: a constituição do sujeito, a produção do valor de uso e a democracia em instituições: o método da roda. São Paulo: Editora Hucitec; 2000.
7. Campos GWS. Considerações sobre a arte e a ciência da mudança: revolução das coisas e reforma das pessoas: O caso da Saúde. In: Cecílio LCO, organizador. Inventando a mudança na Saúde. São Paulo: Editora Hucitec; 1994. p. 29-88.

8. Costa N, Ribeiro JM, Silva PLB. Reforma do Estado e mudança organizacional: um estudo de hospitais públicos. Ciênc Saúde Coletiva 2000; 5:427-42.

9. Aquino EMML. Socorro: quem precisa disso? Um estudo sobre usuários de serviços de emergência no Município do Rio de Janeiro [Dissertação de Mestrado]. Rio de Janeiro: Instituto de Medicina Social, Universidade do Estado do Rio de Janeiro; 1987.

10. Sá MC, Azevedo CS. Trabalho gerencial e processos intersubjetivos: uma experiência com diretores de hospitais públicos. Rev Adm Pública 2002; 36:50727.

11. Cecilio LCO. É possível trabalhar o conflito como matéria-prima da gestão em saúde? Cad Saúde Pública 2005; 21:508-16. 
12. Azevedo CS, Braga Neto FC, Sá, MC. O Indivíduo e mudança nas organizações de saúde: contribuições da Psicossociologia. Cad Saúde Pública 2002; 18:235-47.

13. Enriquez E. Les jeux du pouvoir et du désir dans l'éntreprise. Paris: Desclée Brouwer; 1997.

14. Enriquez E. A organização em análise. Petrópolis: Editora Vozes; 1997.

15. Enriquez E. Instituições, poder e "desconhecimento”. In: Araújo JNG, Carreteiro TC, organizadores. Cenários sociais e abordagem clínica. São Paulo: Escuta/Belo Horizonte: Fundação Mineira de Educação e Cultura; 2001. p. 49-74.

16. Merhy EE. Saúde: cartografia do trabalho vivo. São Paulo: Editora Hucitec; 2002

17. Kaës R. O grupo e o sujeito do grupo: elementos para uma teoria psicanalítica do grupo. São Paulo: Casa do Psicólogo; 1997.

18. Carreteiro TC. História de vida: da genealogia a um estudo. Psico (Porto Alegre) 2003; 34:281-95.

19. Pineau G, Legrand JL. Les histoires de vie. Paris. Presses Universitaires de France; 1993.

20. Bertaux D. Les récits de vie. Paris: Éditions Nathan; 1997.

21. Gaulejac V, Levy A. Recits de vie et histoire sociale. Paris: Eska Éditions; 2000.

22. Carreteiro TC. A doença como projeto: uma contribuição à análise de formas de afiliações e desafiliações sociais. In: Bader S, organizador. As artimanhas da exclusão: análise psicossocial e ética da desigualdade social. Petrópolis: Editora Vozes; 2001. p. 87-95.

23. Bauman Z. O mal-estar da pós-modernidade. Rio de Janeiro: Jorge Zahar Editor; 1998.

24. Santos BS. Pela mão de Alice: o social e o político na pós-modernidade. São Paulo: Cortez Editora; 2001.

25. Ehrenberg A. La fadiga de ser uno mismo. Buenos Aires: Ediciones Nueva Visión; 2000
26. Birman J. Mal-estar na atualidade. Rio de Janeiro: Civilização Brasileira; 1999.

27. Aubert N. Le culte de l'urgence. Paris: Flammarion; 2003.

28. Mendes EV. Uma agenda para saúde. São Paulo: Editora Hucitec; 1996.

29. Castoriadis C. A instituição imaginária da sociedade. Rio de Janeiro: Editora Paz e Terra; 1982.

30. Fernandes MIA. Mestiçagem e ideologia: algumas reflexões sobre a negatividade na construção de vínculos sociais [Tese de Livre Docência]. São Paulo: Instituto de Psicologia, Universidade de São Paulo; 2003.

31. Kaës R. O intermediário na abordagem psicanalítica da cultura. Psicol USP 2003; 14:15-34.

32. Dejours C. Parte II: a clínica do trabalho. In: Lancman S, Sznelwar L, organizadores. Cristophe Dejours: da psicopatologia à psicodinâmica do trabalho. Rio de Janeiro: Editora Fiocruz/Brasília: Paralelo 15; 2004. p. 197-276.

33. Dejours C. A carga psíquica do trabalho. In: Dejours C, Abdoucheli E, Jayet C, organizadores. Psicodinâmica do trabalho: contribuições da escola Dejouriana à análise da relação prazer, sofrimento e trabalho. São Paulo: Editora Atlas; 1994. p. 21-32.

34. Barus-Michel J. Sofrimento, trajetos, recursos. Dimensões piscossociais do sofrimento humano. In: Aiello-Vaisberg T, Ambrosio FF, organizadores. Trajetos do sofrimento: rupturas e (re)criações de sentido. São Paulo: Instituto de Psicologia, Universidade de São Paulo; 2003.

35. Giust-Deprairies F. Crise. In: Barus-Michel J, Enriquez E, Lévy A, organizadores. Vocabularie de psychosociologie. Paris: Éditions Éres; 2002. p. 10817

Recebido em 12/Mai/2006

Versão final reapresentada em 01/Nov/2006 Aprovado em 12/Abr/2007 